\title{
SLEEP PATTERN ANALYSIS AND IMPROVEMENT USING ARTIFICIAL INTELLIGENCE AND MUSIC THERAPY
}

\author{
Dr. M. Durai Pandian, \\ Professor, Department of CSE, \\ Vivekananda College of Engineering, \\ Namakal, India. \\ Email id: svsduraipandian@gmail.com
}

\begin{abstract}
The rapid growth in the population and the changes endured in the lifestyle of the people increases the demand for the healthcare segments that does a continuous monitoring of the heath. The artificial intelligence that has been engaged in the numerous of real-life applications, has caused a greater impact in the very basic facet of the human life such as the communication, interaction, education, driving, entertainment and has been limited to the heath monitoring. For decades it is the artificial intelligence is been utilized in the health care for the analysis and the diagnosis of the disease, for assisting the surgical methodologies etc. has also been utilized in the improving the health of the person by monitoring the quality of the sleep they have. The paper puts forth a sleep pattern analysis using the artificial intelligence and the therapy based on the music for improving the sleeping time and reducing the stress according to the quality of the sleep evaluated.
\end{abstract}

Keywords: Sleep Pattern, Music Therapy, Support Vector Machine, Actimetry Sensor, controller, Driver circuit.

\section{INTRODUCTION}

The research and the expert physician say that seven to eight hours of sleep is required for the normal person who is in his adolescent stage, middle or the elderly stage and this could increase for the new borns and the infants of age 4 to 10. The sleep duration plays a vital role in the performance as well as health of the person. The reduced sleep duration would result in the heart attacks and many other serious diseases that cause fatalities. The experts say that the according to the sleep duration the sleep pattern also changes and they also mention the age as the reason for the changes experienced in the sleep duration. Sometimes even the stress that was endured as the reason for the changes in the sleep duration. The figure.1below presents the stages in the sleep cycle. 
Journal of Artificial Intelligence and Capsule Networks (2019)

Vol.01/ Issue.02

Pages: 54-62

http://irojournals.com/aicn/

DOI: https://doi.org/10.36548/jaicn.2019.2.001

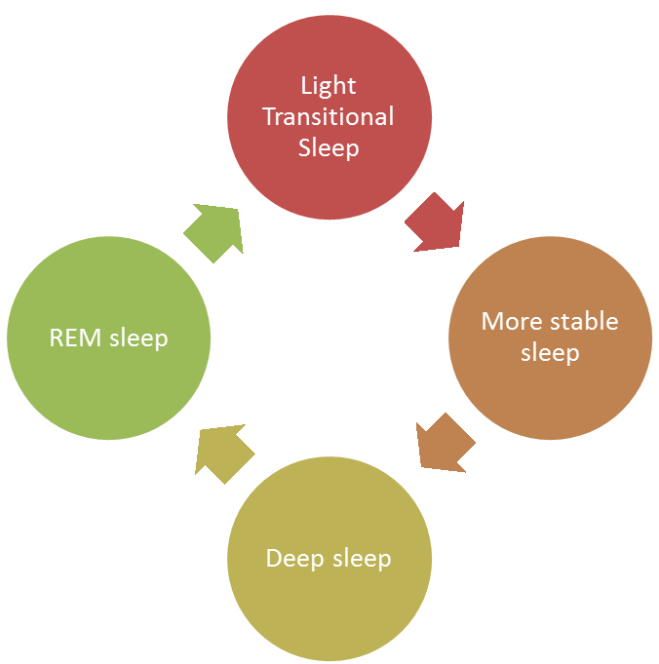

Fig.1 Sleep Stages

The fig. 1 shows usual stages that a human passes through to take a nap. It clearly states that the person crosses the four cyclic stages before his nap time that takes duration of 90 to 120 minutes. Doctors' advice the sleep is very important for the proper functioning of the brain, the nerve cells and all the organs in the body that include the heart, lungs, metabolism, immune system, mind and the disease resistance.

From the latest research it was found that the artificial intelligence intervene more in improving the sleep time of the individual by analyzing the sleep pattern and presenting the sleep scoring to the persons.

The proposed system for the evaluating the sleep time also put forward the artificial intelligence in the analysis of the sleep pattern and utilizes the music therapy to enhance the sleep duration based on the sleep levels that was monitored. So the method utilizes the support vector machine in classifying the sleep stages to enable the music therapy to regulate the sleep disorders

The remaining paper is arranged with the 2 , related works, 3 . The proposed work utilizing the artificial intelligence in sleep pattern analysis, 4 . The result and the discussion and 5. Conclusion. 
Journal of Artificial Intelligence and Capsule Networks (2019)

Vol.01/ Issue.02

Pages: 54-62

http://irojournals.com/aicn/

DOI: https://doi.org/10.36548/jaicn.2019.2.001

\section{RELATED WORKS}

Carswell, et al [1] the paper provides the systematic review of the assisted technology in monitoring the health of the people affected with the dementia and the therapies that can be provided to improve the health of the patients.

O'Kelly et al [2] the author put forward a study based on the neurophysiology and the behavior of the patient response in the vegetative state and the minimal conscious state based on the music therapy given to him.

WEI, et al [3] the author present the success in the brain computing interface utilizing the electroencephalography signal to solve the problems in the music information retrieval and analyzing the sleep quality. The quality of the sleep is analyzed using the EEG signals with the feature extraction and the classification based on the SVM, the output of the classifier in the project is send to the 3D visualizer as well as the music game module to play a music based on sleep quality analyzed.

Raglio et al [4]. the study proceeded in the paper is about the "music therapy to reduce the condition of the stress that is aggravated due to the work or any other reasons. Harwood et al [5] author puts forward the "role of the artificial intelligence in the taking care of the aged" McNamara et al [6] the usage of the artificial intelligence in the classification of the dream content is proffered in the paper

Papakostas, et al [7] the paper utilizes the various machine learning and the deep learning methods for the analysis of the activities and the signal generated from the human brain and the whole body system, by engaging a multimodal user monitoring.

Wagner et al [8] the artificial intelligence used in various real time application has also been put forth in the medical field for the maintaining the "patients record, diagnosing the disease, assisting in the surgical procedure, and offering mental health therapy" and so on, the article presents the review of the usage of the artificial intelligence in the medical imaging along with the essential 1 qualities in it and how useful it remains for the humans.

Khojandi et al [9] the "EEG signals of the obtained from the twenty patients are classified using the random forest into various sleep stages and the semi-Markov decision process is utilized to evaluate the optimal intervention policies so as to bring down the gap in the various stages of the sleep. 
Journal of Artificial Intelligence and Capsule Networks (2019)

Vol.01/ Issue.02

Pages: 54-62

http://irojournals.com/aicn/

DOI: https://doi.org/10.36548/jaicn.2019.2.001

Ravan et al [10] the proposed approach put forward in the paper is to gather the sleep score and improve the sleep quality utilizing the Vagus nerve stimulation. To classify the quality of the sleep based on the three stages light sleep, + REM and deep sleep the paper has put forth the multi-class SVM classifier that relies on the decision tree.

O'Caoimh et al [11] the author present the systematic review based meta-analysis on the non-pharmacological treatments for improving the sleep quality, in the patients with the mild cognitive impairment and the dementia. Kallipolitis et al [12] the "speed up robust features for the emotional analysis in the hospital bedside infotainment platforms is proffered in the paper". Jensen et al [13] the employment of the "ROBOTS and the health monitoring devices for taking care of the sickly patient in a house is put forward in the paper.

\section{PROPOSED WORK}

The sleep pattern analysis has become a deep entailment in our day today lives to regulate our sleep disorders and improve the health status of an individual. So the proposed system analysis the sleep pattern by extracting the features and classifying the stages of the sleep using the support vector machine[3], with the level of the sleep being noted down turn on the music system to enable a music therapy to the user. The fig .2 below shows the block diagram of the proposed work that combines the artificial intelligence and the music therapy in regulating the sleeping disorders. 
Vol.01/ Issue.02

Pages: 54-62

http://irojournals.com/aicn/

DOI: https://doi.org/10.36548/jaicn.2019.2.001

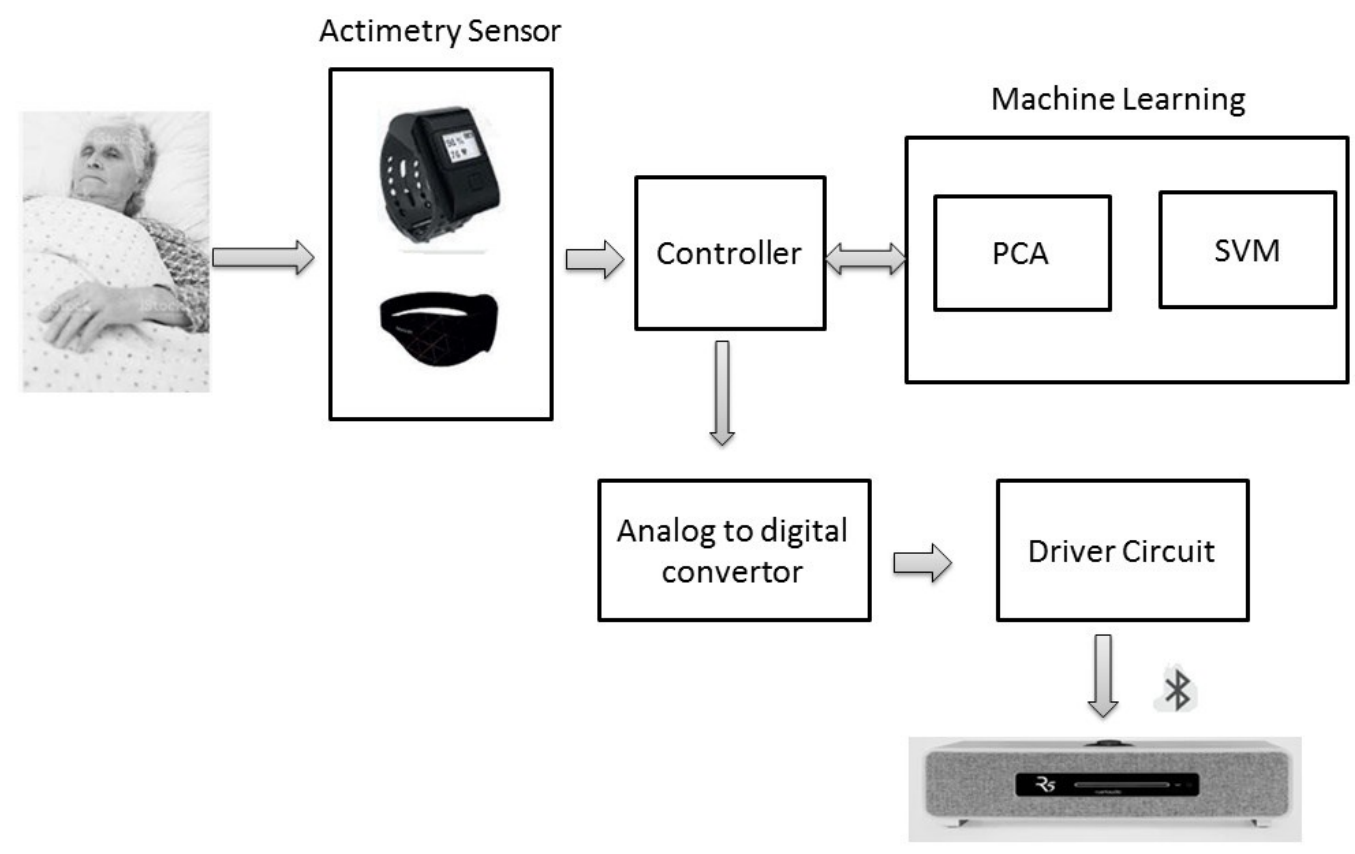

Music System

Fig.2. Block Diagram of Proposed Work

The Actimetry sensors in the form of the wrist watch or head band worn in the hand or the head of the user is utilized in monitoring the sleep activities of the individual such as the sleep quality, the sleep onset latency, the total duration of the sleep, the body movement, the sleep cycle and the total time that is spent on the bed. The information gathered are subjected to the feature extraction using the principal component analysis [3], the extracted feature are sent to the support vector machine that is previously trained with the normal sleep activities that was acquired from 20 healthy persons. It is then utilized to predict the pattern of the sleep whether it is light sleep or a less stable sleep deep sleep.

The level of the sleep monitored are converted into voltages based on the threshold using the analog to digital convertor set for each state and fed to the driver circuit to turn on and off the music system that is loaded with the lullabies that put a person to sleep. where the threshold for the deep sleep state is set as negative value that is recognized as the low level by the analog to digital convertor and, the threshold for the less stable and the light sleep state are set as positive values that is recognized as the high level for the ADC. If the output of the ADC is high the driver circuit is turned on and switches on the music system otherwise turns off the driver circuit in turn the

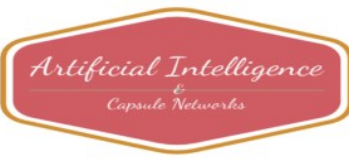


Journal of Artificial Intelligence and Capsule Networks (2019)

Vol.01/ Issue.02

Pages: 54-62

http://irojournals.com/aicn/

DOI: https://doi.org/10.36548/jaicn.2019.2.001

music system is turned off. So by utilizing the proposed method the sleep pattern of the person is analyzed and the remedy for the disorders found in the sleeping is done utilizing the music therapy. This system would be more suited for the aged people who have very poor sleeping duration, the infants and the person with the abnormal sleeping practices. The proffered system could be used only in a smaller area where the human intervention is required for loading the music system with the appropriate Songs disc.

\section{RESULTS AND DISCUSSION}

The proffered model is tested gathering the sleep pattern of a group of $20-40$ persons that consisted of people between the ages of 4-10,11-20, 25-35, $40-50$ and 55-70. The prediction of the sleep quality based on the observations that was held for a week was measured in term of the accuracy and precision. The fig. 3 shows the sleep cycle of the normal person (observed from 20 individuals of prime age) that was used in training the SVM.

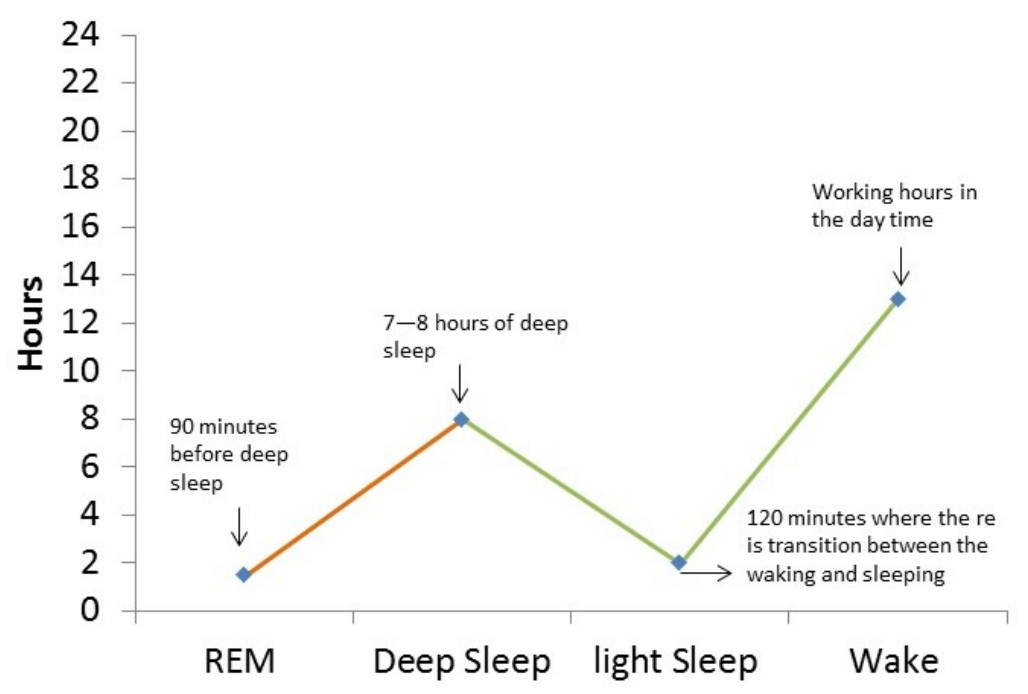

Fig.3 Normal Sleep Cycle

The prediction results for the test data provided based on the observation from the $20-40$ persons of age 4-10, 11$20,25-35,40-50$ and 55-70, that was held for a week is measured in terms of the accuracy and the precision is represented below in the table. 1 below.

ISSN: 2582-2012 (online) 
Journal of Artificial Intelligence and Capsule Networks (2019)

Vol.01/ Issue.02

Pages: 54-62

http://irojournals.com/aicn/

DOI: https://doi.org/10.36548/jaicn.2019.2.001

\begin{tabular}{|l|l|l|l|l|l|l|l|l|l|l|l|l|l|l|}
\hline \multirow{2}{*}{ Age Group } & \multicolumn{2}{|l|}{ Day 1 } & \multicolumn{2}{l}{ Day2 } & \multicolumn{2}{l|}{ Day3 } & \multicolumn{2}{l|}{ Day4 } \\
\cline { 2 - 12 } & $\begin{array}{l}\text { Accu } \\
\text { racy }\end{array}$ & $\begin{array}{l}\text { Preci } \\
\text { sion } \\
\%\end{array}$ & $\begin{array}{l}\text { Accu } \\
\text { racy } \\
\%\end{array}$ & $\begin{array}{l}\text { Preci } \\
\text { sion } \\
\%\end{array}$ & $\begin{array}{l}\text { Accu } \\
\text { racy } \\
\%\end{array}$ & $\begin{array}{l}\text { Preci } \\
\text { sion } \\
\%\end{array}$ & $\begin{array}{l}\text { Accu } \\
\text { racy } \\
\%\end{array}$ & $\begin{array}{l}\text { Preci } \\
\text { sion } \\
\%\end{array}$ & $\begin{array}{l}\text { Accu } \\
\text { racy } \\
\%\end{array}$ & $\begin{array}{l}\text { Preci } \\
\text { sion } \\
\%\end{array}$ & $\begin{array}{l}\text { Accu } \\
\text { racy } \\
\%\end{array}$ & $\begin{array}{l}\text { Preci } \\
\text { sion } \\
\%\end{array}$ & $\begin{array}{l}\text { Accu } \\
\text { racy } \\
\%\end{array}$ & $\begin{array}{l}\text { Preci } \\
\text { sion } \\
\%\end{array}$ \\
\hline $4-10$ & 96 & 85 & 97 & 93.5 & 95 & 85 & 96 & 88 & 96 & 85 & 97 & 85 & 95 & 91 \\
\hline $11-20$ & 97 & 84 & 94 & 95 & 95.5 & 89 & 94 & 87 & 97 & 84 & 94 & 89 & 99 & 95 \\
\hline $25-35$ & 95 & 87 & 98 & 90 & 97 & 86 & 92 & 84 & 95 & 87 & 98 & 86 & 97 & 90 \\
\hline $40-50$ & 98 & 88 & 99 & 89 & 98 & 84 & 93 & 85 & 98 & 88 & 99 & 84 & 98 & 89 \\
\hline $55-70$ & 99 & 89 & 95 & 88 & 95 & 83 & 98 & 89 & 99 & 89 & 95 & 87 & 95 & 88 \\
\hline
\end{tabular}

Table.1. Accuracy and Precision Percentage

The measure shows the accuracy and the precision of the proposed method in the sleep pattern analysis and the improvement achieved in the sleep quality by utilizing the music therapy for a week for the people belonging to different age groups.

\section{CONCLUSION}

The paper for improving the sleeping duration and regulating the sleeping disorders utilizes the artificial intelligence for the analyzing the sleeping pattern engaging the Support vector machine to classify the sleep pattern. Further the output of the classification is fed to the music module using the controller and the driver circuit that turns on the music system via Bluetooth. Based on the sleep level measured the music system turns on or off to enhance the sleep duration of the individual. The performance of the system utilizing the artificial intelligence and the music therapy was found to be promising on the terms of accurate measurement of the sleep quality and the therapy provided in return. The system could be utilized inside a room within a house or a hospital to enhance the sleep duration of the elderly, infants and the sickly. Further the paper is to proceed with the comprehensive study on the sleep pattern

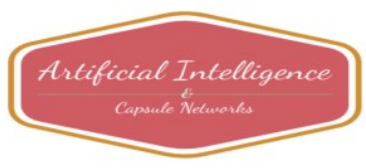


Journal of Artificial Intelligence and Capsule Networks (2019)

Vol.01/ Issue.02

Pages: 54-62

http://irojournals.com/aicn/

DOI: https://doi.org/10.36548/jaicn.2019.2.001

analysis using the deep learning in combination with the artificial intelligence to automate all the process and reduce the human intervention.

\section{References}

[1] Carswell, William, P. J. McCullagh, Juan Carlos Augusto, Suzanne Martin, M. D. Mulvenna, H.Zheng, H. Y. Wang et al. "A review of the role of assistive technology for people with dementia in the hours of darkness." Technology and Health Care 17, no. 4 (2009): 281-304.

[2]. O'Kelly, Julian, L. James, Ramaswamy Palaniappan, J. Fachner, J. Taborin, and Wendy L. Magee. "Neurophysiological and behavioral responses to music therapy in vegetative and minimally conscious states." Frontiers in Human Neuroscience 7 (2013): 884.

[3] WEI, ZHAO. "Utilizing EEG signal in music information retrieval." PhD diss., 2010.

[4] Raglio, A., D. Bellandi, M. Gianotti, E. Zanacchi, M. Gnesi, M. C. Monti, C. Montomoli et al. "Daily music listening to reduce work-related stress: a randomized controlled pilot trial." Journal of Public Health (2019).

[5] Harwood, Tracy, Elizabeta Mukaetova-Ladinska, and John Maltby. "Role of Artificial Intelligence (AI) art in care of ageing society: Focus on dementia." (2019).

[6] McNamara, Patrick, Kelly Duffy-Deno, and Tom Marsh. "Dream content analysis using Artificial Intelligence." International Journal of Dream Research (2019): 42-52.

[7] Papakostas, Michalis. "FROM BODY TO BRAIN: USING ARTIFICIAL INTELLIGENCE TO IDENTIFY USER SKILLS \& INTENTIONS IN INTERACTIVE SCENARIOS." PhD diss., 2019.

[8] Wagner, Jessyca B. "Artificial Intelligence in Medical Imaging." Radiologic technology 90, no. 5 (2019): 489501.

[9] Khojandi, Anahita, Oleg Shylo, and Maryam Zokaeinikoo. "Automatic EEG classification: a path to smart and connected sleep interventions." Annals of Operations Research 276, no. 1-2 (2019): 169-190.

[10] Ravan, Maryam, and Jason Begnaud. "Investigating the Effect of Short Term Responsive VNS Therapy on Sleep Quality Using Automatic Sleep Staging." IEEE Transactions on Biomedical Engineering (2019).

[11] O’Caoimh, Rónán, Helen Mannion, Duygu Sezgin, Mark R. O’Donovan, Aaron Liew, and D. William Molloy. "Non-pharmacological treatments for sleep disturbance in mild cognitive impairment and dementia: A systematic review and meta-analysis." Maturitas (2019).

[12] Kallipolitis, A., M. Galliakis, Andreas Menychtas, and Ilias Maglogiannis. "Emotion Analysis in Hospital Bedside Infotainment Platforms Using Speeded up Robust Features." In IFIP International Conference on Artificial Intelligence Applications and Innovations, pp. 127-138. Springer, Cham, 2019. 
Journal of Artificial Intelligence and Capsule Networks (2019)

Vol.01/ Issue. 02

Pages: 54-62

http://irojournals.com/aicn/

DOI: https://doi.org/10.36548/jaicn.2019.2.001

[13] Jensen, Elizabeth AG, Justin Smith, and Christine R. Kovach. "Social Robots, Robotic Assistants, and Home Health Monitoring Devices: A Gerontological Research Perspective." Research in gerontological nursing 12, no. 4 (2019): 163-166. 